\title{
Assessment of Vulnerability to Climate Change using a Multi-Criteria Outranking Approach with Application to Heat Stress in Sydney
}

\author{
Abbas El-Zein* and Fahim N Tonmoy \\ School of Civil Engineering, University of Sydney, NSW 2006, Australia. \\ *Corresponding author. \\ Email: abbas.elzein@sydney.edu.au Phone: +61 293517351
}

\begin{abstract}
Climate change vulnerability assessment is a complex form of risk assessment which accounts for both geophysical and socio-economic components of risk. In indicator-based vulnerability assessment (IBVA), indicators are used to rank the vulnerabilities of socioecological systems (SESs). The predominant aggregation approach in the literature, sometimes based on multi-attribute utility theory (MAUT), typically builds a global-scale, utility function based on weighted summation, to generate rankings. However, the corresponding requirement for additive independence and complete knowledge of system interactions by analyst are rarely if ever satisfied in IBVA.
\end{abstract}

We build an analogy between the structures of Multi-Criteria Decision Analysis (MCDA) and IBVA problems and show that a set of techniques called Outranking Methods, developed in MCDA to deal with criteria incommensurability, data uncertainty and preference imprecision, offer IBVA a sound alternative to additive or multiplicative aggregation. We reformulate IBVA problems within an outranking framework, define thresholds of difference and use an outranking method, ELECTRE III, to assess the relative vulnerability to heat stress of 15 local government areas in metropolitan Sydney. We find that the ranking outcomes are robust and argue that an outranking approach is better suited for assessments characterized by a mix of qualitative, semi-quantitative and quantitative indicators, threshold effects and uncertainties about the exact relationships between indicators and vulnerability.

Key Words: multiple criteria analysis; climate change; vulnerability assessment; aggregation; outranking procedures; heat stress 


\subsection{Introduction}

Climate change adaptation is emerging as a significant field of research in a number of disciplines. It is premised on the fact that, even under the most optimistic scenarios of greenhouse gas emission reduction over the next hundred years, some degree of change in climate appears inevitable. Assessments of the vulnerability of a valued utility (e.g., health, shelter, security, economic prosperity) for a given population (e.g., locality, community, economic sector) to one or more climate-related hazards (e.g., heat waves, flood events, rise in sea levels) serve as planning tools in environmental decision-making. They help in identifying highly vulnerable communities, allocating adaptation resources, better understanding systemic weaknesses, monitoring the effects of adaptation measures, communicating risk and justifying policy to the public (Eriksen and Kelly, 2007; Füssel, 2007; Klein, 2003).

A large number of climate-related vulnerability studies can be found in the literature. Some vulnerability studies are based on mechanistic or economic modelling, especially those evaluating the impacts of climate stress on specific biological systems or economic sectors, usually agricultural (e.g., Belliveau et al., 2006; Gbetibouo et al., 2010; Luers et al., 2003). Others, often indicator-based, map vulnerabilities across geographical areas at a given scale (e.g., Hahn et al., 2009; O'Brien et al., 2004; Vincent, 2007; Wilhelmi et al., 2004). These assessments are generally meant to be precursors for more in-depth, impact analyses of vulnerable populations. We refer to assessments of vulnerability that are totally or partly based on indicators as indicator-based vulnerability assessments (IBVA). Although IBVA approaches have been applied to stressors other than climate (e.g., famine and poverty), in this paper we are concerned exclusively with climate-related stresses.

Most vulnerability assessment frameworks recognize both the external, geophysical determinants of risk, called exposure to climate stressors, and the internal, socio-economic and institutional processes generating vulnerability, usually referred to as the system's sensitivity to the stress in question and its adaptive capacity or lack thereof (Eriksen and Kelly, 2007; Klein, 2003; Parry, 2007). These are sometimes called the three dimensions of vulnerability and are seen as the outcome of the interaction of two traditions of vulnerability research in physical and social sciences-a synthesis that provides a better account of the contextual and social dynamics of climate hazards and the multiple linkages that govern their impacts (Adger, 2006; Füssel, 2007).

Proxy indicators are customarily used to construct indices of vulnerability to different stressors under each one of the above dimensions. The exercise is rendered more complex by conceptual and heuristic difficulties (what is vulnerability? by what proxies can it represented? what are the 
processes that reproduce it?) as well as methodological ones (poor prediction of climate variables at regional and local scales; quality of data; difficulty of quantifying the behaviour of socio-ecological systems). The usefulness of indicator-based vulnerability comparisons of nations has been called into question because of poor understanding of the complexity of processes generating vulnerability at that scale, as well as inconsistencies in data aggregation (Eriksen and Kelly, 2007; Klein, 2009).

One of the most significant methodological challenges of vulnerability metrics is to convert a selected set of indicators into a ranking of comparable socio-ecological systems, according to their vulnerabilities to one or more climate hazards. This process of aggregation is usually performed through weighted summation, sometimes on the basis of multi-attribute utility theory (MAUT). MAUT is a member of the family of Multi-Criteria Decision Analysis (MCDA) methods and can provide a powerful decision analysis approach that is widely used in economics, engineering, decision science and development studies. However, when weighted summation is used in the context of IBVA, its theoretical requirements are difficult to achieve in practice. As an example, additive aggregation typically converts indicators into comparable scales before building an additive utility function; this requires the additive independence of indicators, which is virtually impossible in IBVA (Clemen and Reilly, 1999). The uncertainties attached to stakeholder preference are not usually taken into account (Hinkel, 2011a). For example, a methodology developed by de Chazal et al. 2009 to incorporate multiple-agents in vulnerability assessments, nevertheless makes the unlikely assumption of a single, coherent score from each group of stakeholders, hence overlooking variable and/or uncertain opinion within each group. In fact, various sources of uncertainty in vulnerability assessment have been highlighted in the literature, and will be discussed below (Araújo et al., 2005; Barnett, 2001; Füssel and Klein, 2006; Fussel, 2010; Kelly and Adger, 2000; Malone and Brenkert, 2008; Parry et al., 2007; Patt et al., 2005b; Vincent, 2007). While some have argued that probabilities of impacts ought to be used in choosing adaptation options (New et al., 2007), probability distributions are much more difficult to use in conjunction with the social dimensions of vulnerability, especially adaptive capacity (Dessai et al., 2009).

The theoretical and practical challenges posed by aggregation of MCDA problems have been recognized by many authors (Böhringer and Jochem, 2007; Clemen and Reilly, 1999; Ebert and Welsch, 2004; Füssel, 2007; Greco, 2004; Hinkel, 2011b; Keeney and Raiffa, 1993; Klein, 2009). However, to the best of our knowledge, no paper on vulnerability to climate change has focused on this issue from an IBVA perspective, even less suggested alternatives to utility-based approaches for IBVA. There is clearly a need for aggregation methods that can tackle the problems discussed above (e.g., uncertainty, lack of common scale for indicators and absence of additive independence of 
indicators). Our paper is concerned with this particular methodological problem. Specifically, we argue for a different approach to the generation of vulnerability rankings. The approach, based on a family of techniques known as Outranking Methods, generates rankings of comparable objects through structured pair-wise comparisons without resorting to a utility function. Three significant advantages of these methods are that they a) do not convert non-commensurate variables into a common scale and can hence more easily aggregate indicators of different scales (e.g. cardinal, ordinal, interval) and different nature (e.g., environmental, social, economic etc), b) do not require indicator additive independence and c) can better accommodate uncertainty in preference structures and imprecision in measured conditions than conventional additive aggregation procedures (Polatidis et al., 2006). Outranking methods, first proposed by Roy 1968, were developed in the field of multi-criteria decision analysis (MCDA), a sub-discipline of decision science, in order to aid policy-makers in choosing between different alternative actions under conflicting criteria and a high level of uncertainty (Brooks, 2003; Figueira. J, 2005; Hokkanen and Salminen, 1997; Kangas. A, 2001). Outranking approaches have been criticized for axiomatic violations such as rank reversal and intransitivity, as well as difficult data requirements in large, complex problems (Figueira; et al., 2010; Wang and Triantaphyllou, 2008). Nevertheless, they appear to have strong descriptive validity and have been successfully deployed in a range of decision-making contexts (De Boer et al., 1998; El Hanandeh and El-Zein, 2010; Geldermann et al., 2000; Hokkanen and Salminen, 1997; Kangas et al., 2001; Papadopoulos and Karagiannidis, 2008; Pohekar and Ramachandran, 2004).

We reformulate IBVA problems within an outranking framework and apply a widely-used outranking method, ELECTRE-III, to assess the relative vulnerabilities to heat stress of 15 local government areas (LGA) in metropolitan Sydney. We compare additive and multiplicative aggregation to ELECTRE III aggregation and assess the robustness and sensitivity of ELECTRE III rankings. For the remainder of the paper, we adopt a definition of vulnerability, generally agreed upon in the literature, as a measure of potential harm, in the present or future, to one or more valued attributes of a socioecological system from single or multiple hazards (Brooks, 2003; Füssel, 2007; Füssel., 2004; Luers et al., 2003; Metzger et al., 2005).

In the remainder of the paper, we first describe major sources of uncertainty in IBVA then present the problem of aggregation and the challenges emanating from it. Next, we develop an outranking framework for aggregation as an alternative to global-utility aggregation. We illustrate fundamental features of the proposed framework through a simple example. Finally, we apply the methodology to the assessment of vulnerability to heat of a number of 15 local councils in Sydney and compare rankings generated by the outranking approach to those yielded by additive and multiplicative 
aggregations.

\subsection{Uncertainty in Indicator-Based Vulnerability Assessments}

Uncertainty in any assessment of vulnerability to climate change emanates from a number of sources, at both the biophysical and social ends of the analysis. The most significant uncertainty is arguably an epistemic one attached to predictions of global circulation models (GCMs) and due to processes and feedback mechanisms that are unknown, poorly understood or difficult to quantify (Füssel and Klein, 2006; Heal and Kriström, 2002; Patt et al., 2005a; Reilly et al., 2001). The process of downscaling GCM predictions to regional and local levels adds another layer of uncertainty mostly due to unknown processes at these scales or poor precision due to the spatial resolution of GCMs, or both. All of these sources of uncertainty are important and have received significant attention in the literature (e.g., Adger and Vincent, 2005; Hawkins and Sutton, 2009; New et al., 2007). However, in this paper, we are concerned with the additional uncertainty attached to indicator-based studies that combine the biophysical and socio-economic ends of risk assessment, typically represented by the three dimensions of exposure, sensitivity and adaptive capacity. These assessments either start from a climate-change scenario and attempt to quantify vulnerability at some point in the future or they might study vulnerability to climate hazards in the present. Either way, at least three sources of uncertainty need to be considered in the process of indicator selection and manipulation. Following the typology proposed by Walker et al., 2003), we distinguish between three major sources of uncertainty that are relevant in the context of IBVA.

Epistemic uncertainties in contextual understanding operate at the indicator-selection stage. They emanate from incomplete knowledge of processes generating vulnerability, be they biophysical, socio-economic or institutional, and can result in significant deficiencies in indicator-based models. Because IBVA is quantitative, important processes may be overlooked and, for processes that have been identified, suitable indicators may not be available or, if they are, may not be readily quantifiable.

Epistemic uncertainties in understanding model structure (fundamental uncertainties) relate to the exact relationship between indicators and the 'vulnerability' which they are supposed to represent, as well as the relative importance of indicators if a global utility function is used. The two problems are obviously related. These relationships are often unknown, or known only qualitatively. This is due to the combined biophysical and socio-economic nature of the assessments which leads to an inductive and/or normative approach to indicator selection, as opposed to deductive, theory-driven approaches (Hinkel, 2011b; Vincent, 2007). Deductive approaches are difficult to develop and, in 
making them operational, researchers often come up against the problem of lack of availability of suitable data. As a result, it is practically impossible to select a set of additively independent indicators, generate a one-on-one correspondence between indicators and processes producing vulnerability or establish mechanistically the way indicators should be combined to reflect vulnerability generated by a combination of processes. Instead, the selection and aggregation of indicators depends in part on information provided by the stakeholders, either as a source of knowledge about the system or as the expression of preferences.

Statistical uncertainty in system data (imprecision) derives from the random and non-random variability of indicator levels, especially if they are averaged over spatial or temporal scales and/or projected into the future. One particular form of imprecision is due to the relatively subjective process by which some indicators (or the weights attached to them, when weights are used) are evaluated. This can be the result of vagueness in individual judgment or variances in the judgment of multiple stakeholders or experts. Imprecision and subjectivity can in principle be quantified with probability distributions, intervals of confidence or fuzzy sets; however, the analysis framework has to recognize and accommodate these uncertainties.

In this paper, the methodology we propose caters for fundamental uncertainties and imprecision. Although we recognize the importance of epistemic uncertainties for IBVA studies, they are beyond our scope here. Specifically, we show that because of the fuzzy structure of outranking methods and the way they build indicators around preference thresholds, incorporating uncertainty related to model structure and system data becomes an intrinsic part of the model building exercise and less likely to be omitted.

\subsection{Aggregation in Indicator-Based Vulnerability Assessment}

The problem of aggregating a number of vulnerability indicators to generate vulnerability rankings can be represented as follows. Let $s_{j}=\left\{s_{1}, \ldots ., s_{n}\right\}$ be a set of $n$ comparable socio-ecological systems (SES) which are to be ranked according to the vulnerability of a valued attribute to one or more climate hazards based on a set of $m$ indicators $I_{i}=\left\{I_{1}, \ldots, I_{m}\right\}$. Each indicator has a linear or non-linear relationship to vulnerability, even though it is not always possible to characterize this relationship with precision. A vulnerability matrix $\mathrm{I}_{\mathrm{ij}}(\mathrm{i}=1, \mathrm{~m} ; \mathrm{j}=1, \mathrm{n})$ is constructed whereby each column representing an SES and each row a given indicator, with $I_{i j}$ denoting the value $I_{i}$ for $S_{j}$. If each indicator, independently from the others, yields the same ranking of SESs as all other indicators, no aggregation is needed. This case is of course idealistic and in IBVA, the indicators are almost always conflicting. Depending on the type of aggregation used, a set of weights or votes $w_{i}=\left\{w_{1}, \ldots ., w_{m}\right\}$ may 
be allocated to the set of indicators, with $w_{i}$ reflecting the importance of indicator $l_{i}$ relative to other indicators.

Table 1 clearly shows that the structure of IBVA problems is analogous to multi-criteria decision analysis (MCDA) structure, with alternatives and criteria in the latter becoming SESs and indicators in the former, and similar issues of incommensurability, uncertainty and multiple stakeholders found in both types of problems.

The predominant approach in the literature on vulnerability assessment, based on additive or multiplicative utility functions, consists of converting each indicator into a normalized value on cardinal or ordinal scales or standardizing it relative to a mean, then generating a weighted sum or product as a utility function (Clemen, 1996):

$$
\begin{aligned}
& \mathrm{AM}_{\mathrm{j}}=\frac{1}{\sum_{\mathrm{i}=1}^{\mathrm{m}} \mathrm{w}_{\mathrm{i}}} \sum_{\mathrm{i}=1}^{\mathrm{m}} \mathrm{w}_{\mathrm{i}} \overline{\mathrm{I}}_{\mathrm{ij}} \\
& \mathrm{GM}_{\mathrm{j}}=\sqrt[m]{\prod_{\mathrm{i}=1}^{\mathrm{m}} \overline{\mathrm{I}}_{\mathrm{ij}}}
\end{aligned}
$$

where $A M_{j}$ and $\mathrm{GM}_{\mathrm{j}}$ are additive (arithmetic mean) and multiplicative (geometric mean) utility functions for SES $j$, respectively; $\overline{\mathrm{I}}_{\mathrm{ij}}$ is the normalized version of vulnerability matrix $\mathrm{I}_{\mathrm{ij}}$. Vulnerabilities of SESs are ranked based on the values of $\mathrm{AM}_{\mathrm{j}}$ or $\mathrm{GM}_{\mathrm{j}}$. Henceforth, we will refer to procedures using (1) as Arithmetic Aggregation and those using (2) as Geometric Aggregation. This approach is not confined to climate research and is widely used in the literature on environmental and human development indices (Barnett et al., 2008; Bohle et al., 1994; Cutter et al., 2003; Preston et al., 2008; Rygel et al., 2006)

The use of utility functions for building indices has generated some debate in the literature. For example, Ebert and Welsch, 2004 analysed both additive and multiplicative aggregations in relation to a specific validity criterion, namely that the resulting index should yield identical rankings when different normalizations or standardisations are used. They found that multiplicative aggregations have better validity than additive ones, and better reflect synergetic processes between indicators. However, multiplicative aggregation can be difficult to communicate to stakeholders and experts. Munda and Nardo, 2009 argued that a Condorcet approach, based on pairwise comparisons is more suited for building country-based environmental indices. A full review of the literature on indices is beyond the scope of this paper and the reader is referred to Parris and Kates, 2003, Gudmundsson, 2003, Ebert and Welsch, 2004, Böhringer and Jochem, 2007, Barnett et al., 2008 and Munda and 
Nardo, 2009 . Instead, we will focus specifically on IBVA.

IBVA's fundamental uncertainties and imprecision, discussed earlier, make requirements of additive independence and complete knowledge of system interactions by the analyst very difficult to satisfy. For example, a number of socio-economic indicators are typically selected for representing the adaptive capacity of a community (e.g., \% of population with high-school degree, average household income, $\%$ of population in single-parent households); however, these indicators are often correlated and knowledge about the way they might combine to indicate higher or lower vulnerability is very difficult to generate. As a result, IBVA studies commonly use a utility function without providing an objective basis for its construction, especially in relation to the weights applied to each indicator and the assumption of complete compensation between indicators in the case of additive aggregation (El-Zein and Tonmoy, 2014; Hinkel, 2011a; Tonmoy and El-Zein, 2013). Questions such as how much an "advantage" in adaptive capacity make up for an increase in exposure or whether there is a limit beyond which compensation is no longer possible are crucial and yet largely ignored in IBVA. This problem is compounded by the subjective component of the assessment, especially the problem of eliciting perceptions of vulnerability from multiple stakeholders (which, in the MCDA analogy, corresponds to eliciting the preference structure of multiple decision-makers).

We argue therefore that an outranking framework, based on a Condorcet approach and pairwise comparisons, may be better suited to the inherent uncertainty and imperfect knowledge that characterizes IBVA problems, than methods based on additive or multiplicative aggregation, because the theoretical requirements of the former are less stringent. We show that, when eliciting vulnerability perceptions from stakeholders, an outranking method recognizes and foregrounds the uncertainties discussed above.

\subsection{Outranking Framework for IBVA Problems}

\subsection{Background}

A set of methods evolved from the late 1970s to the 1990s, called outranking procedures (OP), as an alternative to MAUT in infrastructure and environmental decision-making studies to deal with the problem of incommensurate criteria and uncertainty. Given that MCDA and IBVA have analogous structures and share similar features (table 1), outranking techniques developed for MCDA are applicable to IBVA. Rather than convert decision criteria into commensurable scales and build a utility function, outranking methods proceed by conducting comparisons of each pair of alternatives 
against each criterion, based on fuzzy preference and indifference relationships, and building a credibility matrix which reflects, on a scale of 0 to 1 , the strength of the statement "Alternative $A$ is at least as good as Alternative B". ELECTRE III is one of the most widely used outranking procedures in the literature especially because, compared to other outranking methods, it offers a more sophisticated characterization of uncertainty in preference structures. For the remainder of the paper, we base our formulation on ELECTRE III; however, other outranking procedures can be considered.

\subsection{ELECTRE III Outranking Procedure}

In ELECTRE III, (El Hanandeh and El-Zein, 2010; Hokkanen and Salminen, 1997; Roy, 1978) the degree to which the pairwise comparisons support the above statement (concordance) AND whether any criterion strongly contradicts it (discordance) are quantified. Concordance is based on a preference threshold, above which a difference in performance between $A$ and $B$ is considered significant and an indifference threshold below which such a difference is insignificant. Discordance is based on a veto threshold which caters for complete incommensurability by allowing a single, excessively high or low, criterion/indicator to alter the ranking of an alternative/SES, regardless of its performance against other criteria/indicators. Hence, by adopting fuzzy definitions of preference, noncompensation and relative compensation, ELECTRE III goes beyond the simple Condorcet model of preference suggested by Munda and Nardo, 2009 and accommodates a wider range of preference configurations. In addition, by using two, ascending and descending ranking pre-orders, it provides an elegant way of eliciting incomparability, i.e. cases when the non-compensatory nature of some indicators yield conflicting relative ranks of two alternatives.

On the other hand, three limitations of ELECTRE have been discussed in the literature: rank reversal, intransitivity and complexity (De Montis et al., 2000; Figueira; et al., 2010). First, intransitivity sometimes occurs in ELECTRE III, whereby decomposing a set of alternatives into smaller analysis sets, under otherwise identical conditions, yields a change in ranking. Figueira; et al., 2010) has shown that this stems from binary relations of indifference which are in fact intransitive and, hence, faithfully mirror decision-making. Second, rank reversal occurs if a non-optimal alternative is replaced with a worse one, all other things equal, and the new ranking yields, counter-intuitively, a change in rankings. (Rank reversal is sometimes referred to in the outranking literature as violation of independence with respect to irrelevant actions). Roy, 1973 and Roy and Martel, 2006 have argued that, rather than a numerical aberration, rank reversal is once again an authentic reflection of real decision-making when data quality is poor and preference structures are uncertain. The extent to 
which rank reversal and intransitivity are present in IBVA, and whether they are acceptable outcomes of the analysis, will need to be considered on a case-by-case basis. It is possible, for example, to assess the robustness of rankings by conducting repeated analyses that test for the existence of rank reversal and intransitivity.

Third, the complexity of the outranking procedure in ELECTRE can be difficult to communicate to stakeholders who tend to prefer simple methods and clear-cut outcomes. However, this is part of a bigger problem of interaction between science and decision-making, with stakeholders sometimes failing to see, and scientists failing to communicate, that assessment methods such as ELECTRE are decision-aiding rather than decision-making tools, especially under high uncertainty (De Montis et al., 2000).

In what follows:

a) We reformulate IBVA problems in an outranking framework, based on ELECTRE III, using a "vulnerability" notation rather than a "decision-making" one.

b) We define thresholds of difference for vulnerability and translate them into verbal questions that can be used in eliciting data from stakeholders for model building, while allowing for the possibility of simulating non-linear relationships between vulnerability and indicators.

\section{Outranking Vulnerability Assessment Framework}

In the presentation below, we assume, without loss of generality, that the higher the value of the indicator, the more vulnerable the SES. For each pair of SESs, we can define three different categories of relative vulnerability:

a) $b$ is strictly more vulnerable than a according to criterion $I_{i}$ if and only if $I_{i b}-I_{i a} \geq p_{i}$, where $\mathrm{p}_{i} \geq 0$ is the relative vulnerability threshold for indicator $l_{i}$;

b) $b$ is indifferent to a according to criterion $I_{i}$ if and only if $\left|I_{i b}-I_{i a}\right| \leq q_{i}$, where $q_{i} \geq 0$ is the indifference threshold for indicator $l_{i}$;

c) $\mathrm{b}$ is weakly more vulnerable than a according to criterion $\mathrm{I}_{\mathrm{i}}$ if and only if $\mathrm{q}_{\mathrm{i}}<I_{\mathrm{ib}}-\mathrm{I}_{\mathrm{ia}}<\mathrm{p}_{\mathrm{i}}$.

The ELECTRE III ranking process is conducted in three stages:

Stage 1: Concordance and Discordance Matrices

A concordance matrix for each indicator $I_{i}$ is defined by: 
$c_{i}(a, b)=\left\{\begin{array}{cc}0 & \text { if } I_{i b}-I_{i a} \geq p_{i} \\ \frac{p_{i}-\left(I_{i b}-I_{i a}\right)}{p_{i}-q_{i}} & \text { if } q_{i}<I_{i b}-I_{i a}<p_{i} \\ 1 & \text { if } I_{i b}-I_{i a} \leq q_{i}\end{array}\right.$

$c_{i}(a, b)$ is a measure of the truth of the statement that "a is at least as vulnerable as b according to indicator I". Note that, it may be more convenient in some cases to write equation 3 in terms of relative rather than absolute differences between indicators; this would require thresholds to be defined as percentages. Equation (3) is a representation of vulnerability as a fuzzy-set relationship shown in figure 1. $p_{i}$ and $q_{i}$ are usually constants; how to determine them is discussed below.

The discordance matrix for each indicator $\mathrm{i}$ is defined by:

$d_{i}(a, b)=\left\{\begin{array}{cc}0 & \text { if } I_{i b}-I_{i a} \leq p_{i} \\ \frac{\left(I_{i b}-I_{i a}\right)-p_{i}}{v_{i}-p_{i}} & \text { if } p_{i}<I_{i b}-I_{i a}<v_{i} \\ 1 & \text { if } I_{i b}-I_{i a} \geq v_{i}\end{array}\right.$

where $v_{i}$ is called dominance threshold for indicator $\mathrm{i}$ and reflects a difference between indicator values above which $b$ becomes more vulnerable than $a$, regardless of the performances of $a$ and $b$ on other indicators. We will refer to $\mathrm{q}_{\mathrm{i}}, \mathrm{p}_{\mathrm{i}}$ and $\mathrm{v}_{\mathrm{i}}$ collectively as thresholds of difference to emphasize that they provide a reference for disparities between indicators rather than the indicators themselves.

\section{Stage 2: Outranking Matrix}

The statement " $a$ is at least as vulnerable as b" (denoted $\mathrm{aVb}$ ) is considered true provided:

i. a "majority" of indicators supports it (concordance principle);

and

ii. no single indicator vetoes it (discordance principle).

The concordance principle can be measured by the following concordance index:

$\mathrm{C}(\mathrm{a}, \mathrm{b})=\frac{1}{\sum_{\mathrm{i}=1}^{\mathrm{m}} \mathrm{w}_{\mathrm{i}}} \sum_{\mathrm{i}=1}^{\mathrm{m}} \mathrm{w}_{\mathrm{i}} \mathrm{c}_{\mathrm{i}}(\mathrm{a}, \mathrm{b})$

where $\mathrm{w}_{\mathrm{i}}$ is a vote for indicator $\mathrm{I}_{\mathrm{i}}$, applied to the pair-wise comparisons, rather than a weight in a global utility function, that is, it modifies the concordance values $c_{i}$, rather than the indicators in the vulnerability matrix. An outranking matrix combines the concordance and discordance principles in order to quantify the degree to which $\mathrm{aVb}$ is true. It is given by: 
$S(a, b)=\left\{\begin{array}{lr}C(a, b) & \text { if } d_{i}(a, b) \leq C(a, b) \forall i=1, m \\ C(a, b) \prod_{i \in I_{v}(a, b)} \frac{\left[1-d_{i}(a, b)\right]}{[1-C(a, b)]} & \text { otherwise } \\ \text { where } I_{v}(a, b) \text { is the set of indicators for which } d_{i}(a, b)>C(a, b)\end{array}\right.$

Stage 3: Distillation and Ranking Procedures

The most vulnerable SES is the one that outranks the largest number of SESs and is outranked by least. Hence, $S(a, b)$ is used next to build two partial, descending and ascending pre-orders $D_{1}$ and $D_{2}$ as follows. A matrix T can be defined as:

$\mathrm{T}(\mathrm{a}, \mathrm{b})=\left\{\begin{array}{lr}1 & \text { if } \mathrm{S}(\mathrm{a}, \mathrm{b}) \geq \lambda-\mathrm{g}(\lambda) \\ 0 & \text { otherwise }\end{array}\right.$

where $\lambda=\max S(a, b)$ and $g(\lambda)$ is a threshold of indifference applied to the outranking matrix in such a way that only values of $S(a, b)$ close enough to $\lambda$ yield $T(a, b)=1 . g(\lambda)$ is typically set at 0.15 (Vallée and Zielniewicz, 1994) when $\lambda=1$ or, more generally, at $-0.15 \lambda+0.3$. Therefore, $g(\lambda)$ represents a cut-off point of "defuzzification", ie the conversion of the continuous scale of the outranking matrix into a binary one that is used to generate final rankings. Hence, sensitivity of rankings to $g(\lambda)$ will need to be assessed. The sum of rows in $T(a, b)$ computes the number of SESs for which $\mathrm{aVb}$ is true, while the sum of columns is the number of SESs for which bVa is true. A vector $Q(a)$ is defined as the difference between these two sums:

$\mathrm{Q}(\mathrm{a})=\sum_{\mathrm{k}=1}^{\mathrm{m}} \mathrm{T}(\mathrm{a}, \mathrm{k})-\sum_{\mathrm{k}=1}^{\mathrm{m}} \mathrm{T}(\mathrm{k}, \mathrm{a})$

Equation (8) is used to generate two ascending $\left(D_{1}\right)$ and descending $\left(D_{2}\right)$ pre-orders and a final ranking as $\mathrm{D}_{1} \cap \mathrm{D}_{2}$.

\subsection{Determination of Thresholds of Difference}

In aggregating indicators for an IBVA problem, the most important advantages of an outranking approach such as ELECTRE III are as follows:

a) no conversion of indicators into a normalized scale is performed; pair-wise comparisons of SESs on each criterion are conducted instead and aggregation is performed on the outcome of these comparisons (concordance index) rather than a normalized indicator;

b) the analyst is compelled to spell out assumptions about compensation and noncompensation between indicators at the outset, through the definitions of $v_{i}$ and $w_{i}$, with the possibility of specifying complete compensation, complete non-compensation, as well as a degree of compensation in between (discordance matrix). 
c) the analyst is compelled to quantify fundamental uncertainties discussed above, at the outset, through the definitions of $q_{i}, p_{i}$ and $g(\lambda)$.

The determination of thresholds $q_{i}, p_{i}$ and $v_{i}$, as well as the votes $w_{i}$ is therefore an important part of problem definition. In vulnerability terms, they can be defined, and determined, by the following questions:

1. "All other indicators being equal, what is the difference in values of indicator $\mathrm{I}_{\mathrm{i}}$ for two SESs below which the vulnerabilities of the two systems are the same?" (indifference threshold qi).

2. "All other indicators being equal, what is the difference in values of indicator $l_{i}$ for two SESs above which one system is strictly more vulnerable than the other?" (relative vulnerability threshold $\mathrm{p}_{\mathrm{i}}$ ).

3. "What is the difference in values of indicator $I_{i}$ for two SESs above which one system is strictly more vulnerable than the other AND no advantage by any other indicator, or combination of other indicators, can compensate for it?" (dominance threshold $\mathrm{v}_{\mathrm{i}}$ ).

4. "In determining whether a 'majority' of indicators support the statement that one SES is at least as vulnerable as another, what is the strength of the 'vote' by indicator $I_{i}$ relative to a reference indicator?" (vote $\mathrm{w}_{\mathrm{i}}$ ).

The preposition "All other indicators being equal" is used only for the purpose of eliciting thresholds for individual indicators and that, in generating rankings, the outranking analysis considers of course ALL indicators together. Note that we have tested questions 1 to 4 in a separate project in which we interviewed stakeholders in order to elicit thresholds, for the purpose of assessing vulnerability to sea-level rise of 8 small coastal communities south of Sydney; we will be reporting this research in the future.

In the literature on MCDA, different methods for calculating the thresholds have been proposed (e.g., Roy, 1978; Rogers and Bruen, 1998; Roy et al., 1986). M. Maystre, 1994 argues that $q$ and $p$ should be interpreted as minimum and maximum margins of uncertainty, respectively. However, in IBVA, the two thresholds can reflect uncertainty, imprecision, subjectivity or non-linearity. For example, small differences between indicators may be too small to indicate differences in vulnerability $\left(q_{i}\right)$ because a) they fall within statistically random or non-random fluctuations of the indicator (e.g., as they are up-scaled to the spatial level of the analysis); b) stakeholders have offered a normative judgment about the nature of the indicator in its relationship with vulnerability or c) a non-linear relationship has been mechanistically established between indicator and vulnerability. 
Which of these three approaches to setting thresholds is used will depend on the indicator in question and, given the mix of biophysical, institutional and socio-economic indicators in IBVA, a mix of approaches would be expected. More generally, the elicitation of a preference structure from stakeholders is subject to ongoing research in the outranking community and the reader is referred to Beroggi, 2000 and Kodikara et al., 2010 for more details on this.

It is important to keep in mind that the approach we are proposing attempts to capture the "vulnerability" of an SES and the approach is, at least on this account, descriptive. On the other hand, since vulnerability depends on both "objective" risk factors (e.g., sea level rise, proximity to coastline, physiological or economic sensitivity of population to risk) and "subjective" or "normative" factors (e.g., risk perception, relative importance of valued attributes to the community), the proposed approach "prescribes" a way of capturing and combining these factors. What makes an outranking approach attractive for vulnerability assessment, therefore, are the fuzzy and noncompensatory properties of the methods, rather than the historical impetus for their emergence, ie replicating human decision-making structures. As a consequence, despite the strong "descriptive" element of the approach, validating it by somehow measuring vulnerability independently, is not possible.

\subsection{Illustrative Example}

Table 2 illustrates fundamental outranking relations and their effects on vulnerability assessment using a simple hypothetical model of 3 SESs and 3 indicators. The nine scenarios shown have the same vulnerability matrix but different thresholds of difference. Equal votes $w_{i}$ are given to the three indicators. Case 1 represents a scenario in which all pairwise differences between indicators are smaller than the relevant indifference threshold and all SESs are equally vulnerable. Moving to cases 2-4, the thresholds for $I_{2}$ and $I_{3}$ remain the same, while those of $I_{1}$ change. In case 2 , all $I_{1}$ differences $\left(\left|I_{1}-I_{2}\right| ;\left|I_{2}-I_{3}\right|\right.$ and $\left.\left|I_{3}-I_{1}\right|\right)$ fall between $q_{i}$ and $p_{i}$ : vulnerability is determined by $I_{1}$ and increases linearly with it. In case $3, q_{i}$ and $p_{i}$ for $I_{1}$ lead to both strict and weak relative vulnerabilities. If the $I_{1}$ indifference threshold is increased to 1.1, as happens in case 4, then SES2 and SES3 have equal vulnerabilities because $\left|I_{12}-I_{13}\right|<q_{1}$. In case 5 , the first two indicators determine the final ranking, because the differences between indicators cover all three cases of indifference, weak and strict relative vulnerabilities. In this case, unlike the previous ones, the respective votes given to indicators have some impact on the outcome. Case 6 demonstrates the effect of the dominance threshold, now set to $3.5 \%$ for $I_{2}$, whereby SES3 cannot be found to be more vulnerable than SES1, regardless 
of the pair's performance on other indicators. In case 7, there is vulnerability dominance of SES3 over SES1 according to $I_{1}$ and vice versa according $I_{2}$. Likewise, SES2 has contradictory dominance relationships with SES1 and SES3. Hence, incomparability arises which reflects conflicting indicators AND complete absence of compensation when differences exceed the dominance threshold. Case 8 is similar to case 7 except that incompatible dominance occurs only between SES1 and SES3 and a partial ranking is obtained. Finally, in case 9, all indicators influence the outcome, with various levels of "strict vulnerability", "weak vulnerability" and "indifference", as well as "dominance" occurring.

\subsection{Real-Life Application : Vulnerability to Heat Stress in Sydney}

We adapted an indicator-based model of vulnerability to climate change for 15 Local Government Area (LGA) in Sydney, first developed by Preston et al., 2008. The LGA is a statistical division of local government in Australia. The 15 LGAs, shown in Figure 2, were originally selected because they form a group of coastal councils interested in developing climate adaptation policies. Sydney, like other cities in Australia and elsewhere, suffers from higher mortality on hot days (e.g., Hu et al., 2008; Vaneckova et al., 2008) Vulnerability to heat was represented by a set of 6 indicators representing exposure, 4 indicators for sensitivity and 12 indicators for adaptive capacity (see Table 3). Preston et al., 2008) developed a conceptual model of vulnerability to heat stress for Sydney where exposure and sensitivity indicators were based on predictors of heat-related mortality and morbidity from the epidemiological literature. Adaptive capacity indicators were based on the capacity to access material capital, financial resources and so on. For further details on the rationale behind the selection, we refer the reader to Preston et al., 2008). A measure of error for each indicator was inferred or collected from data descriptors and methodologies provided by the sources, and used to derive thresholds. The full vulnerability matrix, as well as the data sources and the thresholds, are given in table A1 of the Appendix for the base case. Both the Spearman's and Pearson's correlation factors were used to compare sets of rankings, although only the former is shown because the two factors yielded consistent results.

The presence of rank reversal was systematically tested by re-analysing the base case with one LGA withdrawn at a time and rankings compared to those of the base case. This was conducted for all LGAs except the most and least vulnerable. The rankings were found to be robust, with the first and last LGA never changing and an average and minimum Spearman coefficients, relative to the base case, of 0.94 and 0.92 , respectively. Where rank reversal did occur, it was around the middle ranks where the relatively small differences in scores between LGAs makes them more prone to instability. Sensitivity of rankings to changes in $g(\lambda)$ (up to $\pm 33 \%$ ) were also tested and results were found, once 
again, robust.

Table 4 shows vulnerability rankings of the 15 LGAs for the base case. All three aggregation methods (ELECTRE III, arithmetic and geometric) identify Rockdale, Botany Bay and Randwick as the most vulnerable and Mosman, Pittwater and Hornsby as the least vulnerable. The former three have relatively low values of adaptive capacity indicators, although Botany Bay and Rockdale's exposures are ranked high as well. Interestingly, Rockdale is ranked ninth in terms of sensitivity but still comes first overall on account of its relatively low adaptive capacity. Hornsby and Pittwater have large areas covered with vegetation and therefore low urban heat island effect (represented by the last three indicators of exposure), whereas Mosman is an LGA with a large proportion of population with a high socio-economic background. "Sydney", which denotes the Central Business District, has high exposure as a result of the urban heat-island effect but relatively low sensitivity because its population does not include a large proportion of over 65 and under 4 .

Arithmetic aggregation and ELECTRE III yield similar but not identical rankings. This is expected for the base case because $q_{i}$ and $p_{i}$ reflect a relatively small amount of uncertainty, no non-linearity and no dominance $\left(v_{i}=\infty\right)$. The differences between the rankings generated by, on the one hand, Geometric aggregations and, on the other hand, arithmetic and ELECTRE III aggregations, are rather large because the geometric aggregation is multiplicative and therefore synergetic, i.e., it penalises more heavily LGAs with low performance in more than one indicator, regardless of any thresholds or weights. Nevertheless, the same groups of the three most and three least vulnerable LGAs are identified by the three methods, and the variations in rankings occur in the group of LGAs that fall between these two extremes.

The sensitivity of ELECTRE III rankings to thresholds of difference and to votes are shown in Table 5. Rankings are robust under changes of up to $100 \%$ in $q_{i}$ and $p_{i}$. As expected, the introduction of dominance thresholds for all indicators has a bigger impact on rankings than changes in $\mathrm{q}_{i}$ and $\mathrm{p}_{\mathrm{i}}$, with a Spearman correlation factor of 0.84 when $v_{i}=2 p_{i}$. The last six rows in Table 5 show the change in rankings when votes in ELECTRE III and weights in Arithmetic aggregation are increased by $100 \%$ for all indicators of one dimension at a time, while the ratios of the remaining weights in the weighted mean calculations are kept constant. It should be noted that, in the analyses reported in Table 5, all 22 indicators were lumped together (non-hierarchical aggregation) to generate vulnerability ranking. . Outranking results are once again robust to changes in votes, and the rankings of Arithmetic aggregation are more sensitive to changes in weights of sensitivity and adaptive capacity indicators, compared to the equivalent outranking sensitivity to votes. This is due 
to the fact that votes in ELECTRE III are applied to the concordance matrix generated from the pairwise comparisons, rather than a utility function.

\subsection{Conclusions}

Additive aggregation procedures have remained dominant in the IBVA literature despite the fact that their theoretical requirements of additive independence and complete system knowledge are almost never satisfied in the context of IBVA. We have argued here that outranking procedures, previously only applied to decision-making problems, can be used for vulnerability assessment and may provide a better approach for teasing out policy-relevant information from uncertain vulnerability data.

Outranking procedures implicitly recognize the quantitative and qualitative dimensions of the assessment and work with descriptive categories that are matched with the level of quantitative sophistication of available data. One interesting effect of this is that, as we showed earlier, outranking procedures can yield incomparability of two SESs, usually as a result of conflicting dominance thresholds and absence of compensation. Indeed, an outranking approach forces the analyst to spell out and characterize the degree of uncertainty in the relationship between indicator and vulnerability, while allowing for a mix of cardinal and ordinal variables to be included. The process of building the indicator-based model can in fact be structured around the four questions we proposed as a way of determining difference thresholds and votes because they provide a systematic way of canvassing proposed indicators and bringing to the fore assumptions underlying the model.

Furthermore, outranking methods yield rankings and ranking-based scores rather than indices. This, we believe, is both a limitation and a strength in the context of IBVA. It is a limitation because it does not allow us to compare indices calculated in different studies and different contexts, albeit following a common, benchmarked procedure-which is what indices are meant to do. Nor does it tell us how vulnerable a given SES is, only whether it is more or less vulnerable than another SES. It is a strength because it highlights the comparative nature of index-building, and a sometimes forgotten fact that, while we may be able to compare vulnerabilities, we cannot measure them or reduce them to a single variable.

Our research raises a number of questions. Are some outranking procedures better suited for IBVA than others? How can non-linearities be incorporated in the outranking aggregation process? In a preliminary investigation, we found that non-linear relationships between indicator and vulnerability 
can be represented in outranking procedures by extending the definitions of relative vulnerability and indifference thresholds. This research is ongoing and will be reported in a separate paper. Developing a mathematical typology of thresholds and non-linearities in models of exposure, sensitivity and adaptive capacity may be another suitable starting point for such research. To our knowledge, very little can be found in the literature on this. On the other hand, applying outranking procedures in actual multi-stakeholder assessment exercises would help in further refining and extending the proposed approach. Of particular interest is the extent to which the four questions we used to define thresholds and votes are effective in eliciting them from data, experts and stakeholders.

\section{References}

Adger, W.N., 2006. Vulnerability. Global Environmental Change 16, 268-281.

Adger, W.N., Vincent, K., 2005. Uncertainty in adaptive capacity. Comptes Rendus Geoscience 337, 399-410.

Araújo, M.B., Whittaker, R.J., Ladle, R.J., Erhard, M., 2005. Reducing uncertainty in projections of extinction risk from climate change. Global Ecology and Biogeography 14, 529-538.

Barnett, J., 2001. Adapting to climate change in Pacific Island Countries: The problem of uncertainty. World Development 29, 977-993.

Barnett, J., Lambert, S., Fry, I., 2008. The hazards of indicators: insights from the environmental vulnerability index. Annals of the Association of American Geographers 98 102-119.

Belliveau, S., Smit, B., Bradshaw, B., 2006. Multiple exposures and dynamic vulnerability: Evidence from the grape industry in the Okanagan Valley, Canada. Global Environmental Change 16, 364-378.

Beroggi, G.E., 2000. An experimental investigation of preference elicitation methods in policy decision-making. Journal of Multi-Criteria Decision Analysis 9, 76-89.

Bohle, H.G., Downing, T.E., Watts, M.J., 1994. Climate change and social vulnerability: Toward a sociology and geography of food insecurity. Global Environmental Change 4, 37-48.

Böhringer, C., Jochem, P.E.P., 2007. Measuring the immeasurable - A survey of sustainability indices. Ecological Economics 63, 1-8.

Brooks, N., 2003. Vulnerability, Risk and Adaptation: A Conceptual Framework, Working Paper 38. Tyndall Centre for Climate Change Research, University of East Anglia, Norwich.

Clemen, R.T., 1996. Making hard decisions: an introduction to decision analysis.

Clemen, R.T., Reilly, T., 1999. Making hard decisions with DecisionTools Suite.

Cutter, S.L., Boruff, B.J., Shirley, W.L., 2003. Social Vulnerability to Environmental Hazards. Social Science Quarterly 84, 242-261.

De Boer, L., van der Wegen, L., Telgen, J., 1998. Outranking methods in support of supplier selection. European Journal of Purchasing \& Supply Management 4, 109-118.

de Chazal, J.R., Mark D. A., 2009. Land-use and climate change within assessments of biodiversity change: A review. Global Environmental Change 19, 306-315.

De Montis, A., Toro, P., Droste-Franke, B., Oman, I., Stagl, S., 2000. MCDA and Sustainable Development-A Comparison of Methods, Proceedings of World Meeting Man and City-towards a human and sustaianable development, Università degli Studi di Napoli Federico II.

Dessai, S., Hulme, M., Lempert, R., Pielke Jr, R., 2009. Climate prediction: a limit to adaptation?, The SCAM Project: Simplicity, Complexity, and Modelling, pp. 64-78.

Ebert, U., Welsch, H., 2004. Meaningful environmental indices: A social choice approach. Journal of Environmental Economics and Management 47, 270-283. 
El-Zein, A., Tonmoy, F.N., 2014. Nonlinearity, fuzziness and incommensurability in assessments of vulnerability to climate change: a new framework Environmental Modeling \& Software (Under Review).

El Hanandeh, A., El-Zein, A., 2010. The development and application of multi-criteria decision-making tool with consideration of uncertainty: The selection of a management strategy for the biodegradable fraction in the municipal solid waste. Bioresource Technology 101, 555-561.

Eriksen, S., Kelly, P., 2007. Developing Credible Vulnerability Indicators for Climate Adaptation Policy Assessment. Mitigation and Adaptation Strategies for Global Change 12, 495-524.

Figueira. J, G.S., M. Ehrgott,, 2005. Multiple Criteria Decision Analysis: State of the Art Surveys. Springer, New York.

Figueira;, J.R., Greco;, S., Roy;, B., Slowinski, R., 2010. ELECTRE methods: Main Features and Recent Developments, in: Zopounidis, C., Pardalos, Panos (Ed.), Handbook of Multicriteria Analysis. Springer, Berlin, pp. 51-89.

Füssel, H.-M., 2007. Vulnerability: A generally applicable conceptual framework for climate change research. Global Environmental Change 17, 155-167.

Füssel, H.-M., Klein, R., 2006. Climate Change Vulnerability Assessments: An Evolution of Conceptual Thinking. Climatic Change 75, 301-329.

Fussel, H.M., 2010. How inequitable is the global distribution of responsibility, capability, and vulnerability to climate change: A comprehensive indicator-based assessment. Global Environmental Change-Human and Policy Dimensions 20, 597-611.

Füssel., J.M., 2004. Coevolution of the political and conceptual frameworks for climate change vulnerability assessments, in: F. Bierman, S.C., K. Jacob (Ed.), Proceedings of the 2002 Berlin Conference on the Human Dimensions of Global Environmental Change "Knowledge for Sustainability Transition: The Challenge for Social Science", Global Governance Project, Berlin.

Gbetibouo, G.A., Ringler, C., Hassan, R., 2010. Vulnerability of the South African farming sector to climate change and variability: An indicator approach. Natural Resources Forum 34, 175-187.

Geldermann, J., Spengler, T., Rentz, O., 2000. Fuzzy outranking for environmental assessment. Case study: iron and steel making industry. Fuzzy sets and systems 115, 45-65.

Greco, S., 2004. Multiple criteria decision analysis: state of the art surveys. Springer.

Gudmundsson, H., 2003. The policy use of environmental indicators - learning from evaluation research. The Journal of Transdisciplinary Environmental Studies 2, 1-12.

Hahn, M.B., Riederer, A.M., Foster, S.O., 2009. The Livelihood Vulnerability Index: A pragmatic approach to assessing risks from climate variability and change-A case study in Mozambique. Global Environmental Change 19, 74-88.

Hawkins, E., Sutton, R., 2009. The potential to narrow uncertainty in regional climate predictions. Bulletin of the American Meteorological Society 90, 1095-1107.

Heal, G., Kriström, B., 2002. Uncertainty and climate change. Environmental and Resource Economics 22, 3-39.

Hinkel, J., 2011a. " Indicators of vulnerability and adaptive capacity": Towards a clarification of the science-policy interface. Global Environmental Change 21, 198-208.

Hinkel, J., 2011b. "Indicators of vulnerability and adaptive capacity": Towards a clarification of the science-policy interface. Global Environmental Change 21, 198-208.

Hokkanen, J., Salminen, P., 1997. ELECTRE III and IV Decision Aids in an Environmental Problem. Journal of Multi-Criteria Decision Analysis 6, 215-226.

$\mathrm{Hu}$, W., Mengersen, K., McMichael, A., Tong, S., 2008. Temperature, air pollution and total mortality during summers in Sydney, 1994-2004. International Journal of Biometeorology 52, 689-696.

Kangas, A., Kangas, J., Pykäläinen, J., 2001. Outranking methods as tools in strategic natural resources planning. Silva Fennica 35, 215-227.

Kangas. A, J.K.a.J.P., 2001. Outranking methods as tools in strategic natural resources planning. Silva Fennica 35, 215-227. 
Keeney, R.L., Raiffa, H., 1993. Decisions with multiple objectives: preferences and value trade-offs. Cambridge University Press.

Kelly, P.M., Adger, W.N., 2000. Theory and practice in assessing vulnerability to climate change andFacilitating adaptation. Climatic Change 47, 325-352.

Klein, R.J.T., 2003. Adaptation to climate variability and change: What is optimal and appropriate?, in: C.Giupponi, M.S. (Ed.), Climate Change in the Mediterranean: Socio-Economic Perspectives of Impacts, Vulnerability and Adaptation. Cheltenham, Edward Elgar, pp. 32-50.

Klein, R.J.T., 2009. Identifying Countries that are Particularly Vulnerable to the Adverse Effects of Climate Change: An Academic or a Political Challenge? CCLR The Carbon \&\#38; Climate Law Review 3, 284-291.

Kodikara, P.N., Perera, B., Kularathna, M., 2010. Stakeholder preference elicitation and modelling in multi-criteria decision analysis-A case study on urban water supply. European Journal of Operational Research 206, 209-220.

Luers, A.L., Lobell, D.B., Sklar, L.S., Addams, C.L., Matson, P.A., 2003. A method for quantifying vulnerability, applied to the agricultural system of the Yaqui Valley, Mexico. Global Environmental Change 13, 255-267.

M. Maystre, J.P., J. Simos, 1994 Methodes multicriteres ELECTRE. EPFL Presses Polytechniques et Universitaires Romandes, Lausanne.

Malone, E., Brenkert, A., 2008. Uncertainty in resilience to climate change in India and Indian states. Climatic Change 91, 451-476.

Metzger, M.J., Leemans, R., Schröter, D., 2005. A multidisciplinary multi-scale framework for assessing vulnerabilities to global change. International Journal of Applied Earth Observation and Geoinformation 7, 253-267.

Munda, G., Nardo, M., 2009. Noncompensatory/nonlinear composite indicators for ranking countries: a defensible setting. Applied Economics 41, 1513-1523.

New, M., Lopez, A., Dessai, S., Wilby, R., 2007. Challenges in using probabilistic climate change information for impact assessments: an example from the water sector. Philosophical Transactions of the Royal Society A: Mathematical, Physical and Engineering Sciences 365, 2117-2131.

O'Brien, K., Leichenko, R., Kelkar, U., Venema, H., Aandahl, G., Tompkins, H., Javed, A., Bhadwal, S., Barg, S., Nygaard, L., West, J., 2004. Mapping vulnerability to multiple stressors: climate change and globalization in India. Global Environmental Change Part A 14, 303-313.

Papadopoulos, A., Karagiannidis, A., 2008. Application of the multi-criteria analysis method Electre III for the optimisation of decentralised energy systems. Omega 36, 766-776.

Parris, T.M., Kates, R.W., 2003. CHARACTERIZING AND MEASURING SUSTAINABLE DEVELOPMENT. Annual Review of Environment and Resources 28, 559-586.

Parry, M.L., Canziani, O.F., Palutikof, J.P., van der Linden, P.J., Hanson, C.E., 2007. Climate change 2007: impacts, adaptation and vulnerability. Intergovernmental Panel on Climate Change.

Parry, M.L., O.F. Canziani, J.P. Palutikof, P.J. van der Linden and C.E. Hanson, 2007. Climate Change 2007: Impacts, Adaptation and Vulnerability. Contribution of Working Group II to the Fourth Assessment Report of the Intergovernmental Panel on Climate Change. Cambridge University Press Cambridge, UK.

Patt, A., Klein, R.J., de la Vega-Leinert, A., 2005a. Taking the uncertainty in climate-change vulnerability assessment seriously. Comptes Rendus Geoscience 337, 411-424.

Patt, A., Klein, R.J.T., de la Vega-Leinert, A., 2005b. Taking the uncertainty in climate-change vulnerability assessment seriously. Comptes Rendus - Geoscience 337, 411-424.

Pohekar, S., Ramachandran, M., 2004. Application of multi-criteria decision making to sustainable energy planning-a review. Renewable and Sustainable Energy Reviews 8, 365-381.

Polatidis, H., Haralambopoulos, D.A., Munda, G., Vreeker, R., 2006. Selecting an appropriate multicriteria decision analysis technique for renewable energy planning. Energy Sources, Part B 1, 181193. 
Preston, B., Smith, T.F., Brooke, C., Gorddard, R., Measham, T.G., Withycombe, G., Beveridge, B., Morrison, C., Mclnnes, K., Abbs, D., 2008. Mapping Climate Change Vulnerability in Sydney Coastal Council Group. Report Available at "http://www.csiro.au/resources/SydneyClimateChangeCoastalVulnerability.html" [19th September 2011].

Reilly, J.M., Stone, P.H., Forest, C.E., Webster, M.D., Jacoby, H.D., Prinn, R.G., 2001. Uncertainty and climate change assessments. MIT Joint Program on the Science and Policy of Global Change.

Rogers, M., Bruen, M., 1998. Choosing realistic values of indifference, preference and veto thresholds for use with environmental criteria within ELECTRE. European Journal of Operational Research 107, 542-551.

Roy, B., 1968. Classement et choix en présence de points de vue multiples (la méthode ELECTRE)'. RIRO 8, 57-75.

Roy, B., 1973. How outranking relation helps multiple criteria decision making, in: Cochrane, J.L., Zeleny, M. (Eds.), multiple criteria decision making. University of South Carolina Press, Columbia, USA.

Roy, B., 1978. ELECTRE III: Un algorithme de classement fondé sur une représentation floue des préférences en présence de critères multiples. Cahiers du Centre d'Etudes de Recherche Opérationnelle 20, 3-24.

Roy, B., Martel, J.M., 2006. Analyse de la signifiance de diverses procédures d'agrégation multicritère. INFOR 44, 191.

Roy, B., Présent, M., Silhol, D., 1986. A programming method for determining which Paris metro stations should be renovated. European Journal of Operational Research 24, 318-334.

Rygel, L., O'sullivan, D., Yarnal, B., 2006. A Method for Constructing a Social Vulnerability Index: An Application to Hurricane Storm Surges in a Developed Country. Mitigation and Adaptation Strategies for Global Change 11, 741-764.

Tonmoy, F.N., El-Zein, A., 2013. Assessment of vulnerability to climate change using indicators: methodological challenges, in: Dincer, I., Colpan, C.O. (Eds.), "Causes, Impacts, and Solutions to Global Warming" Springer (In press).

Vallée, D., Zielniewicz, P., 1994. ELECTRE III-IV, version 3.x - Aspects méthodologiques, Document du LAMSADE no 85, Université de Paris-Dauphine.

Vaneckova, P., Beggs, P.J., de Dear, R.J., McCracken, K.W.J., 2008. Effect of temperature on mortality during the six warmer months in Sydney, Australia, between 1993 and 2004. Environmental Research 108, 361-369.

Vincent, K., 2007. Uncertainty in adaptive capacity and the importance of scale. Global Environmental Change 17, 12-24.

Walker, W.E., Harremoës, P., Rotmans, J., van der Sluijs, J.P., van Asselt, M.B., Janssen, P., Krayer von Krauss, M.P., 2003. Defining uncertainty: a conceptual basis for uncertainty management in modelbased decision support. Integrated assessment 4, 5-17.

Wang, X., Triantaphyllou, E., 2008. Ranking irregularities when evaluating alternatives by using some ELECTRE methods. Omega 36, 45-63.

Wilhelmi, O.V., Purvis, K.L., Harriss, R.C., 2004. Designing a Geospatial Information Infrastructure for Mitigation of Heat Wave Hazards in Urban Areas. ASCE. 
Table 1. Analogy between IBVA and MCDA problems

\begin{tabular}{|c|c|c|c|c|}
\hline & \multicolumn{2}{|l|}{ IBVA } & \multicolumn{2}{|l|}{ MCDA } \\
\hline \multirow{6}{*}{$\begin{array}{l}\text { Problem } \\
\text { Definition }\end{array}$} & \multicolumn{2}{|c|}{$\begin{array}{l}\text { To rank socio-ecological systems according to the } \\
\text { vulnerability of a valuable attribute to one or more } \\
\text { climate hazard }\end{array}$} & \multicolumn{2}{|c|}{$\begin{array}{l}\text { To rank decision alternatives according to their } \\
\text { performances on a set of criteria }\end{array}$} \\
\hline & Socio-Ecological Systems & $\mathrm{S}_{\mathrm{j}}=\left\{\mathrm{S}_{1}, \ldots ., \mathrm{S}_{\mathrm{n}}\right\}$ & Decision Alternatives & $O_{j}=\left\{O_{1}, \ldots . . O_{n}\right\}$ \\
\hline & $\begin{array}{l}\text { Vulnerability-Generating } \\
\text { Processes }\end{array}$ & & Decision Objectives & \\
\hline & Vulnerability Indicators & $\mathrm{I}_{\mathrm{i}}=\left\{\mathrm{I}_{1}, \ldots, \mathrm{I}_{\mathrm{m}}\right\}$ & Attributes/Criteria & $C_{i}=\left\{C_{1}, \ldots, C_{m}\right\}$ \\
\hline & Vulnerability Matrix & $l_{i j}(i=1, m ; j=1, n)$ & Decision Matrix & $R_{i j}(i=1, m ; j=1, n)$ \\
\hline & Indicator Weights/Votes* & $\mathrm{W}_{\mathrm{i}}=\left\{\mathrm{W}_{1}, \ldots ., \mathrm{W}_{\mathrm{m}}\right\}$ & Criteria Weights/Votes* & $W_{i}=\left\{W_{1}, \ldots ., W_{m}\right\}$ \\
\hline \multirow{3}{*}{$\begin{array}{l}\text { Problem } \\
\text { Features }\end{array}$} & \multicolumn{2}{|c|}{ Input from multiple experts and stakeholders } & \multicolumn{2}{|c|}{$\begin{array}{l}\text { Input from multiple decision-makers, experts } \\
\text { and stakeholders }\end{array}$} \\
\hline & \multicolumn{2}{|l|}{ Inconvertibility of indicators } & \multicolumn{2}{|c|}{ Incommensurability of criteria } \\
\hline & \multicolumn{2}{|c|}{ Uncertainties (fundamental; fuzziness; data) } & \multicolumn{2}{|c|}{$\begin{array}{l}\text { Uncertainties (benefits and impacts; fuzziness; } \\
\text { data) }\end{array}$} \\
\hline \multirow{3}{*}{$\begin{array}{l}\text { Thresholds } \\
\text { of } \\
\text { Difference }\end{array}$} & \multicolumn{2}{|l|}{ Indifference Threshold $q_{i}$} & \multicolumn{2}{|l|}{ Indifference Threshold $q_{i}$} \\
\hline & \multicolumn{2}{|c|}{ Relative Vulnerability Threshold $p_{i}$} & \multicolumn{2}{|l|}{ Preference Threshold $p_{i}$} \\
\hline & \multicolumn{2}{|l|}{ Dominance Threshold $v_{i}$} & \multicolumn{2}{|l|}{ Veto Threshold $v_{i}$} \\
\hline
\end{tabular}

*"weights" in MAUT methods become "votes" in outranking methods 
Table 2. Analysis Set 1: Nine Simple Scenarios and Effects of Thresholds on Rankings in ELECTRE III (1: most vulnerable; 3 : least vulnerable)

\begin{tabular}{|c|c|c|c|c|c|c|c|}
\hline Cases & Indicator & $q$ & $p$ & $\mathbf{v}$ & SES1 & SES2 & SES3 \\
\hline \multirow{4}{*}{$\begin{array}{c}\text { Case } 1 \\
\text { Dominated by } \\
\text { indifference }\end{array}$} & $\mathrm{I}_{1}$ & 5 & 6 & $\infty$ & 24 & 27 & 28 \\
\hline & $I_{2}$ & $5 \%$ & $6 \%$ & $\infty$ & $12 \%$ & $11 \%$ & $8 \%$ \\
\hline & $I_{3}$ & $20 \%$ & $30 \%$ & $\infty$ & $50 \%$ & $60 \%$ & $45 \%$ \\
\hline & \multicolumn{4}{|c|}{ Vulnerability Ranking } & 1 & 1 & 1 \\
\hline \multirow{4}{*}{$\begin{array}{c}\text { Case } 2 \\
\text { Dominated by a single, } \\
\text { linear indicator }\end{array}$} & $I_{1}$ & 0 & 8 & $\infty$ & 24 & 27 & 28 \\
\hline & $I_{2}$ & $5 \%$ & $6 \%$ & $\infty$ & $12 \%$ & $11 \%$ & $8 \%$ \\
\hline & $I_{3}$ & $20 \%$ & $30 \%$ & $\infty$ & $50 \%$ & $60 \%$ & $45 \%$ \\
\hline & \multicolumn{4}{|c|}{ Vulnerability Ranking } & 3 & 2 & 1 \\
\hline \multirow{4}{*}{$\begin{array}{c}\text { Case } 3 \\
\text { Dominated by a single, } \\
\text { non-linear indicator }\end{array}$} & $\mathrm{I}_{1}$ & 0.8 & 3.5 & $\infty$ & 24 & 27 & 28 \\
\hline & $\mathrm{I}_{2}$ & $5 \%$ & $6 \%$ & $\infty$ & $12 \%$ & $11 \%$ & $8 \%$ \\
\hline & $\mathrm{I}_{3}$ & $20 \%$ & $30 \%$ & $\infty$ & $50 \%$ & $60 \%$ & $45 \%$ \\
\hline & \multicolumn{4}{|c|}{ Vulnerability Ranking } & 3 & 2 & 1 \\
\hline \multirow{4}{*}{$\begin{array}{c}\text { Case } 4 \\
\text { Dominated by a single, } \\
\text { non-linear indicator }\end{array}$} & $I_{1}$ & 1.1 & 3.5 & $\infty$ & 24 & 27 & 28 \\
\hline & $\mathrm{I}_{2}$ & $5 \%$ & $6 \%$ & $\infty$ & $12 \%$ & $11 \%$ & $8 \%$ \\
\hline & $I_{3}$ & $20 \%$ & $30 \%$ & $\infty$ & $50 \%$ & $60 \%$ & $45 \%$ \\
\hline & \multicolumn{4}{|c|}{ Vulnerability Ranking } & 3 & 1 & 1 \\
\hline \multirow{4}{*}{$\begin{array}{c}\text { Case } 5 \\
\text { Determined by two, } \\
\text { non-linear indicators }\end{array}$} & $\mathrm{I}_{1}$ & 1.1 & 3.5 & $\infty$ & 24 & 27 & 28 \\
\hline & $\mathrm{I}_{2}$ & $1 \%$ & $2 \%$ & $\infty$ & $12 \%$ & $11 \%$ & $8 \%$ \\
\hline & $I_{3}$ & $20 \%$ & $30 \%$ & $\infty$ & $50 \%$ & $60 \%$ & $45 \%$ \\
\hline & \multicolumn{4}{|c|}{ Vulnerability Ranking } & 2 & 1 & 2 \\
\hline \multirow{4}{*}{$\begin{array}{c}\text { Case } 6 \\
\text { Modified by dominance } \\
\text { threshold }\end{array}$} & $I_{1}$ & 1.1 & 3.5 & $\infty$ & 24 & 27 & 28 \\
\hline & $\mathrm{I}_{2}$ & $1 \%$ & $2 \%$ & $3.5 \%$ & $12 \%$ & $11 \%$ & $8 \%$ \\
\hline & $I_{3}$ & $20 \%$ & $30 \%$ & $\infty$ & $50 \%$ & $60 \%$ & $45 \%$ \\
\hline & \multicolumn{4}{|c|}{ Vulnerability Ranking } & 2 & 1 & 3 \\
\hline \multirow{4}{*}{$\begin{array}{c}\text { Case } 7 \\
\text { Incomparable }\end{array}$} & $I_{1}$ & 0 & 0.25 & 0.5 & 24 & 27 & 28 \\
\hline & $I_{2}$ & $0 \%$ & $0.25 \%$ & $0.5 \%$ & $12 \%$ & $11 \%$ & $8 \%$ \\
\hline & $I_{3}$ & $0 \%$ & $2.5 \%$ & $5 \%$ & $50 \%$ & $60 \%$ & $45 \%$ \\
\hline & \multicolumn{4}{|c|}{ Vulnerability Ranking } & - & - & - \\
\hline \multirow{4}{*}{$\begin{array}{c}\text { Case } 8 \\
\text { Partly incomparable }\end{array}$} & $I_{1}$ & 1.1 & 3.5 & 3.8 & 24 & 27 & 28 \\
\hline & $\mathrm{I}_{2}$ & $1 \%$ & $2 \%$ & $3.5 \%$ & $12 \%$ & $11 \%$ & $8 \%$ \\
\hline & $I_{3}$ & $20 \%$ & $30 \%$ & $\infty$ & $50 \%$ & $60 \%$ & $45 \%$ \\
\hline & \multicolumn{4}{|c|}{ Vulnerability Ranking* } & 2 & 1 & 2 \\
\hline \multirow{4}{*}{$\begin{array}{c}\text { Case } 9 \\
\text { All } 3 \text { indicators } \\
\text { influencing outcome }\end{array}$} & $I_{1}$ & 4 & 6 & 8 & 24 & 27 & 28 \\
\hline & $\mathrm{I}_{2}$ & $1 \%$ & $2 \%$ & $3.5 \%$ & $12 \%$ & $11 \%$ & $8 \%$ \\
\hline & $I_{3}$ & $6 \%$ & $11 \%$ & $20 \%$ & $50 \%$ & $60 \%$ & $45 \%$ \\
\hline & \multicolumn{4}{|c|}{ Vulnerability Ranking } & 2 & 1 & 3 \\
\hline
\end{tabular}

*SES2 more vulnerable than SES1 and SES3, but SES1 and SES3 are incomparable to each other 
Table 3. Indicator-based model of vulnerability to heat for 15 local government areas in Sydney (2006 data unless otherwise indicated)

\begin{tabular}{|c|c|c|}
\hline Exposure & Sensitivity & Adaptive Capacity \\
\hline $\begin{array}{l}\text { Present average January maximum } \\
\text { temperature } \\
(2005-2010)\end{array}$ & $\%$ population $\geq 65$ years of age & $\%$ population completing year 12 \\
\hline $\begin{array}{l}\text { Average January minimum } \\
\text { temperature } \\
(2005-2010)\end{array}$ & $\begin{array}{c}\% \text { population } \geq 65 \text { years of age and } \\
\text { living alone }\end{array}$ & $\begin{array}{c}\text { \% population that speaks language } \\
\text { other than English }\end{array}$ \\
\hline $\begin{array}{l}\text { Number of Days }>30^{\circ} \mathrm{C} \text { per Year } \\
(2005-2010)\end{array}$ & $\%$ population $\leq 4$ years of age & Median home loan repayment \\
\hline $\begin{array}{c}\% \text { of impervious land cover (30 m } \\
\text { grid) }\end{array}$ & $\begin{array}{l}\% \text { of housing as multiunit } \\
\text { dwellings }\end{array}$ & $\%$ home ownership \\
\hline Population density & & Median household income \\
\hline \multirow[t]{7}{*}{ Road density } & & $\%$ household with internet access \\
\hline & & $\begin{array}{l}\text { Current ratios of assets to } \\
\text { liabilities of local council }\end{array}$ \\
\hline & & $\begin{array}{l}\text { Per capita business rates of local } \\
\text { council }\end{array}$ \\
\hline & & $\begin{array}{l}\text { Per capita residential rates of local } \\
\text { council }\end{array}$ \\
\hline & & $\begin{array}{l}\text { Per capita community service } \\
\text { expenses of local council }\end{array}$ \\
\hline & & $\begin{array}{l}\text { Per capita environmental and } \\
\text { health expenses of local council }\end{array}$ \\
\hline & & $\begin{array}{l}\% \text { of population requiring financial } \\
\text { assistance }\end{array}$ \\
\hline
\end{tabular}


Table 4. Base case rankings (1: most vulnerable; SCF: Spearman Correlation Factor)

\begin{tabular}{|c|c|c|c|c|c|c|}
\hline & $\begin{array}{l}\text { Arithmetic Mean } \\
\text { All Dimensions }\end{array}$ & $\begin{array}{l}\text { Geometric Mean } \\
\text { All Dimensions }\end{array}$ & $\begin{array}{c}\text { ELECTRE III } \\
\text { All Dimensions a }\end{array}$ & $\begin{array}{l}\text { ELECTRE III } \\
\text { Exposure a }\end{array}$ & $\begin{array}{l}\text { ELECTRE III } \\
\text { Sensitivity a }\end{array}$ & $\begin{array}{c}\text { ELECTRE III } \\
\text { Adaptive } \\
\text { Capacity }{ }^{a}\end{array}$ \\
\hline $\begin{array}{llr}\text { SCF Relative } & \text { to } \\
\text { ELECTRE III } & \text { All } \\
\text { Dimensions } & \end{array}$ & 0.95 & 0.76 & 1 & 0.80 & 0.27 & 0.79 \\
\hline $\begin{array}{ll}\text { SCF Relative } & \text { to } \\
\text { MAUT-Arithmetic All } \\
\text { Dimensions }\end{array}$ & 1 & 0.75 & 0.95 & 0.87 & 0.23 & 0.73 \\
\hline Botany Bay & 2 & 2 & 2 & 3 & 1 & 2 \\
\hline Hornsby & 14 & 15 & 13 & 11 & 15 & 4 \\
\hline Leichhardt & 8 & 4 & 9 & 3 & 13 & 11 \\
\hline Manly & 12 & 9 & 11 & 14 & 2 & 13 \\
\hline Mosman & 13 & 13 & 15 & 11 & 5 & 15 \\
\hline North Sydney & 5 & 7 & 5 & 8 & 5 & 6 \\
\hline Pittwater & 15 & 14 & 14 & 15 & 13 & 12 \\
\hline Randwick & 3 & 3 & 3 & 6 & 9 & 3 \\
\hline Rockdale & 1 & 1 & 1 & 2 & 9 & 1 \\
\hline Sutherland & 7 & 10 & 5 & 6 & 9 & 6 \\
\hline Sydney & 4 & 12 & 4 & 1 & 9 & 4 \\
\hline Warringah & 11 & 5 & 8 & 11 & 5 & 6 \\
\hline Waverley & 6 & 6 & 5 & 3 & 2 & 6 \\
\hline Willoughby & 9 & 8 & 11 & 8 & 9 & 10 \\
\hline Woollahra & 10 & 11 & 9 & 8 & 5 & 13 \\
\hline
\end{tabular}

a. b. Scores for arithmetic and geometric aggregation are normalised on a scale from 0 to 1 over a range determined by the minimum and maximum values of the indicator for the present set of SESs. Here, the single-indicator scale transformation to the neutral 0-1 scale is linear a. Equal weights are assumed for all indicators. 
Table 5. Sensitivity: effects on rankings of changes in thresholds of difference, votes and weights (SCF: Spearman Correlation Factor)

\begin{tabular}{|c|c|c|c|c|}
\hline & & & $\begin{array}{c}\text { SCF Relative to } \\
\text { Base Case } \\
\text { ELECTRE III }\end{array}$ & $\begin{array}{c}\text { SCF Relative to } \\
\text { Base Case MAUT- } \\
\text { Arithmetic }\end{array}$ \\
\hline \multirow{11}{*}{ ELECTRE III } & Base Case & $\begin{array}{l}\text { Base Case* }\left(v_{i}=\infty, p_{i} \text { and } q_{i} \text { as }\right. \\
\text { shown in Table A1 to A3) }\end{array}$ & 1 & 0.94 \\
\hline & \multirow{7}{*}{$\begin{array}{l}\text { Sensitivity to } \\
\text { Thresholds }\end{array}$} & $0.5 q_{i} ; 0.5 p_{i}$ & 0.97 & 0.93 \\
\hline & & $2 q_{i} ; 2 p_{i}$ & 0.94 & 0.93 \\
\hline & & $4 q_{i} ; 4 p_{i}$ & 0.82 & 0.90 \\
\hline & & $v_{i}=4 p_{i}$ & 0.86 & 0.84 \\
\hline & & $v_{i}=2 p_{i}$ & 0.84 & 0.73 \\
\hline & & $g(\lambda)=-0.1 \lambda+0.2$ & 0.99 & 0.90 \\
\hline & & $g(\lambda)=-0.2 \lambda+0.4$ & 0.93 & 0.86 \\
\hline & \multirow{3}{*}{$\begin{array}{l}\text { Sensitivity to } \\
\text { Votes }\end{array}$} & Exposure votes $w_{i}=2$ & 0.95 & - \\
\hline & & Sensitivity votes $w_{i}=2$ & 0.94 & - \\
\hline & & Adaptive capacity votes $w_{i}=2$ & 0.98 & - \\
\hline \multirow{3}{*}{$\begin{array}{l}\text { Arithmetic } \\
\text { Mean }\end{array}$} & \multirow{3}{*}{$\begin{array}{c}\text { Sensitivity to } \\
\text { Weights }\end{array}$} & Exposure weights $w_{i}=2$ & - & 0.98 \\
\hline & & Sensitivity weights $w_{i}=2$ & - & 0.93 \\
\hline & & Adaptive capacity weights $w_{i}=2$ & - & 0.87 \\
\hline
\end{tabular}

*In base case $p_{i}$ and $q_{i}$ are used as shown in table $A 1$ to $A 3$ in the supplementary material 


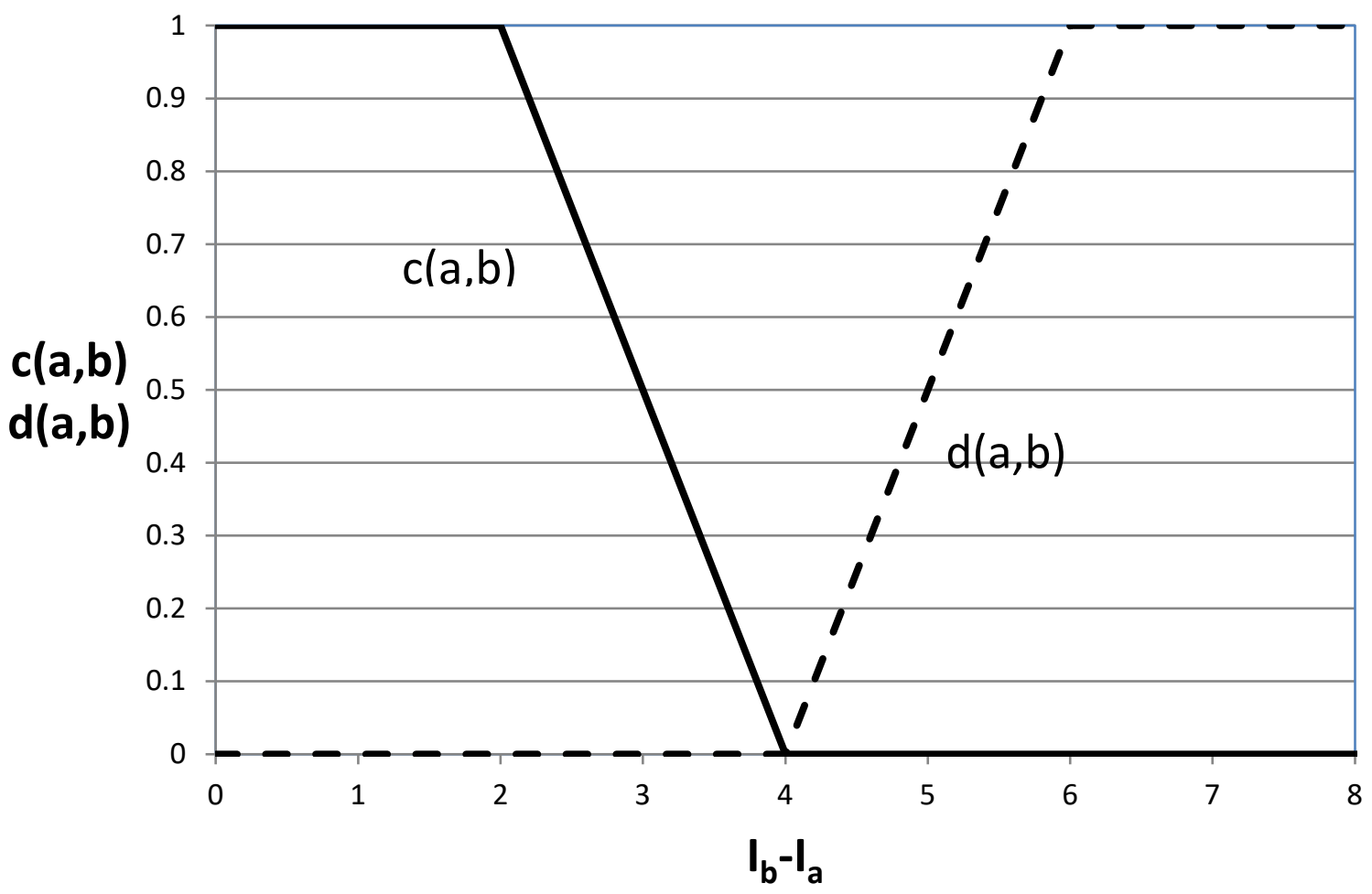

Figure 1. Vulnerability represented by a fuzzy-set relationship : concordance and discordance for $(q=2, p=4, v=6)$ 


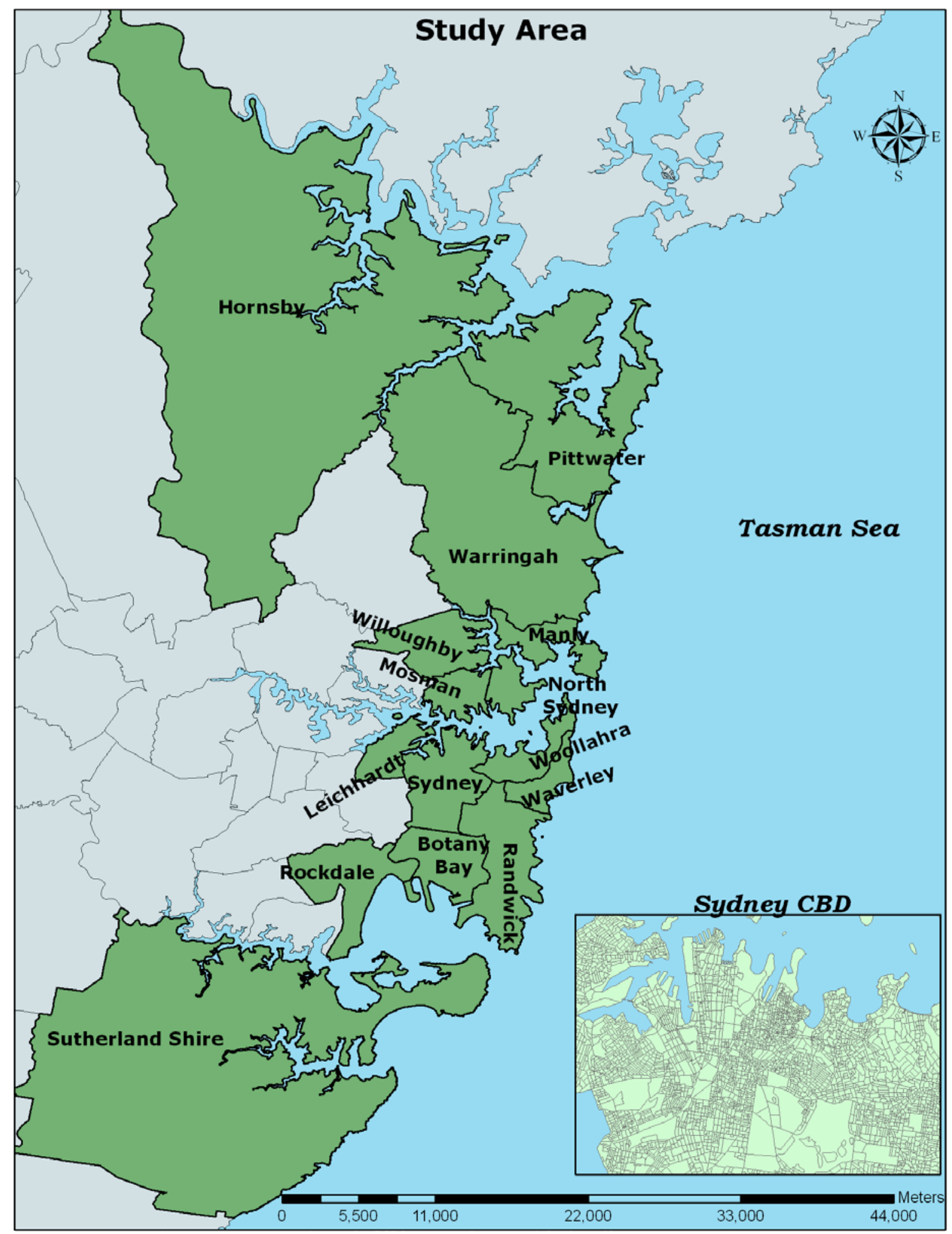

Figure 2. Location of the 15 Local Government Areas referred to in the study 